\title{
Celiac disease in Iran: a systematic review and meta-analysis
}

\author{
Roghayeh Mohammadibakhsh ${ }^{1}$, Rahim Sohrabi ${ }^{2}$, Morteza Salemi ${ }^{3}$, Masood Taheri Mirghaed ${ }^{4}$, Masoud \\ Behzadifar $^{5}$
}

\begin{abstract}
${ }^{1} \mathrm{Ph} . \mathrm{D}$. Student of Health Policy, Hamadan University of Medical Sciences, Hamadan, Iran
${ }^{2}$ Ph.D. Student of Health Policy, Iranian Social Security Organization, Zanjan Province Health Administration, Zanjan, Iran

${ }^{3}$ Ph.D. Student of Health Policy, Social Determinants in Health Promotion Research Center, Hormozgan University of Medical Sciences, Bandar Abbas, Iran

${ }^{4} \mathrm{Ph}$.D. Student of Health Policy, Department of Health Services Management, School of Health Management and Information Sciences, Iran University of Medical Sciences, Tehran, Iran

${ }^{5}$ Ph.D. Student of Health Policy, Health Management and Economics Research Center, Iran University of Medical Sciences, Tehran, Iran
\end{abstract}

Type of article: Meta-analysis

\begin{abstract}
Introduction: Celiac disease (CD) is a chronic autoimmune-mediated disorder with both intestinal and systemic manifestations. The aim of this study was to determine the prevalence of celiac disease in Iran.

Methods: We conducted a systematic search on Embase, Pub Med, Web of Science, Google Scholar, MagIran, Scientific Information database (SID) and Iranmedex from 2003 through to November 2015. The Der-Simonian/ Laird's (DL), with a 95\% confidence interval employed to estimate the overall pooled prevalence. Heterogeneity was investigated by using subgroup analysis based on sample size and time of study.

Results: Sixty-three studies with 36,833 participants met inclusion criteria for analysis. The overall prevalence of celiac disease in 63 studies that had used serological tests for the diagnosis was observed as $3 \%$ (95\% CI: 0.03 0.03 ) and the overall prevalence of celiac disease in studies that had used biopsy method for diagnosis was observed as $2 \%$ (95\% CI: $0.01-0.02)$.

Conclusion: The prevalence of celiac disease in Iran was similar or even higher than world-wide reported.

Keywords: Prevalence, Meta-analysis, Celiac disease, Iran, Systematic review
\end{abstract}

\section{Introduction}

Celiac disease (CD) is one of the most important malabsorption diseases caused by sensitivity to gluten grains in the small intestine. This disease causes inflammation in the small intestine and it can impede the absorption of nutrients (1). Gluten can be found in cereals such as wheat and barley (2). This disease can occur at any age (1). Celiac disease can cause symptoms such as weight loss, growth retardation, osteoporosis, anemia, classic symptoms of malabsorption, chronic constipation, abdominal pain and metabolic bone diseases in patients (3). Signs of mental illness such as depression and cognitive impairment are variable in this disease (4). There are several ways to diagnose celiac disease and using Anti-Tissue Transglutaminase and duodenal biopsy (1). Various studies around the world have investigated the prevalence of celiac disease. IgA-class tissue transglutaminase antibody test has been used in most of these studies. Prevalence of celiac disease in populations of America and Europe has been reported nearly 1\% (5-9). In studies carried out in Finland, Sweden and Mexico based on serology and duodenal biopsy in the general population, the prevalence of celiac disease has been reported about $1 \%(10-12)$. Also in studies conducted on different individuals based on serology, prevalence rate has been reported as $0.7 \%$ in Italy, and $0.3 \%$ in Germany (13). Celiac disease in countries of Eastern Mediterranean Region Organization (EMRO)

\section{Corresponding author:}

Masoud Behzadifar, Health Management and Economics Research Center, Iran University of Medical Sciences, Tehran, Iran. Tel: +98.2166123744, Fax: +98.2166123744, Email:masoudbehzadifar@gmail.com

Received: August 06, 2016, Accepted: January 21, 2017, Published: March 2017

iThenticate screening: November 18, 2016, English editing: February 10, 2017, Quality control: March 02, 2017

(C) 2017 The Authors. This is an open access article under the terms of the Creative Commons Attribution-NonCommercialNoDerivs License, which permits use and distribution in any medium, provided the original work is properly cited, the use is non-commercial and no modifications or adaptations are made. 
including North Africa and the Middle East are increasingly on the rise (6,14-17). Accordingly, it has imposed a lot of economic costs on the respective countries (18). In some studies, this disease has been diagnosed two to three times more in women than in men (19). However, in studies carried out in the general population, a significant difference was not observed between the prevalence of the disease in both sexes $(7,9)$. Increased prevalence of celiac can be due to the high sensitivity of serological tests and more attention to this disease. If just a clinical method is used to diagnose this disease, a large proportion of people may not be diagnosed with the disease (20). Thus, this systematic review and meta-analysis study was conducted to assess the prevalence of celiac disease in Iran. The results may also be helpful in enlightening researchers and policy makers for adopting effective policies and programs to reduce the prevention and prevalence of celiac disease.

\section{Material and Methods}

\subsection{Search methods}

To perform this study and find the related studies, Embase, Pub Med, Web of Science, Google Scholar, MagIran, Scientific Information Database (SID) and Iranmedex databases were searched to December 2015. Searching for studies was carried out in two languages of English and Persian. Moreover, conferences related to celiac disease, and the reference lists of studies were also assessed. For finding the related studies, the keywords based on Medical Subject Headings (MeSH) were used and the search strategy in databases was applied according to title and abstract as "Prevalence" OR "Frequency" AND "Celiac Disease" OR "coeliac disease" AND" Iran “.

\subsection{Study selection}

All Iranian population-based studies in which the prevalence of celiac disease has been reported, the studies in which the diagnostic methods including serological tests and a biopsy of the duodenum have been used according to the Marsh classification (21) and those that their results clearly suggest the prevalence of celiac, were selected as inclusion criteria. Moreover, some researches with the following characteristics were excluded from the study:

1) Case Report, Case Series and Quasi-Experimental studies.

2) Those which lacked appropriate data for estimating prevalence.

3) The studies not conducted based on population.

4) Case Report, Case-Series, Quasi-Experimental and Letter of Editor studies.

5) The studies not applied standard diagnostic method and those with unclear results.

6) Those conducted on non-Iranian population.

\subsection{Data collection}

Two authors independently evaluated title and abstract of studies based on inclusion and exclusion criteria. To increase the quality of the studies, blinding method was used and the authors' names and the journal characteristics were hidden. If there is disagreement between the authors about studies, a third person was asked to act as a judge and resolve disagreements with discussion. The agreement between the two authors to extract information was $95.2 \%$ and the agreement was $81.5 \%$ based on Kappa reliability statistics. After reviewing the studies and finding original studies to analyze, the information contained the name of the first author, year of publication, place of study, the average age in years, the number of positive people by serological test, the number of positive people were extracted by serological test and the number of positive people by duodenal biopsy according to Mesh classification and the type of studies were extracted. All reviews and analyses on literature were conducted based on the PRISMA guidelines.

\subsection{Quality assessment of studies}

After finding studies, the STROBE check list (22) was used to assess their quality. According to items of this checklist, the studies that had all the desired items were classified with high quality, those which lacked two of the items with medium quality and those which lacked more than two items were classified as low quality studies. No study with low quality was excluded. The mean score of all studies was 15.75 .

\subsection{Statistical analysis}

In this meta-analysis, the prevalence was calculated based on Der-Simonian / Laird's (DL) test, using random effects model (23). The findings were presented in Forest Plot graph. All data were reported with 95\% confidence intervals based on random model. To assess heterogeneity between studies, statistical tests I2 and Q-test (24) were used. P-value of less than 0.05 was considered as statistically significant amount. To explore sources of heterogeneities, variables such as publishing year of studies, geographic area of study, sample size, quality of studies and individuals' age were subject to sub-group analysis. Also, to explore more sources of heterogeneity, some 
effective factors such as publishing year and participants' age were meta-regressed according to prior defined variables. To assess publication bias, Egger and Begg tests $(25,26)$ were used. Studies data were given to the Stata 12.0 software (StataCorp LP, College Station, TX) and analyzed.

\section{Results}

In the initial search on databases and reference lists search, 520 studies were eligible, of which, 269 studies were duplicate items. According to the survey conducted on the remaining studies, 93 studies were excluded because of lack of relevance on the subject. The full texts of the 158 studies were investigated. Finally, 63 studies were entered to meta-analysis phase (27-89). Figure (1) shows PRISMA flowchart of selecting the studies.

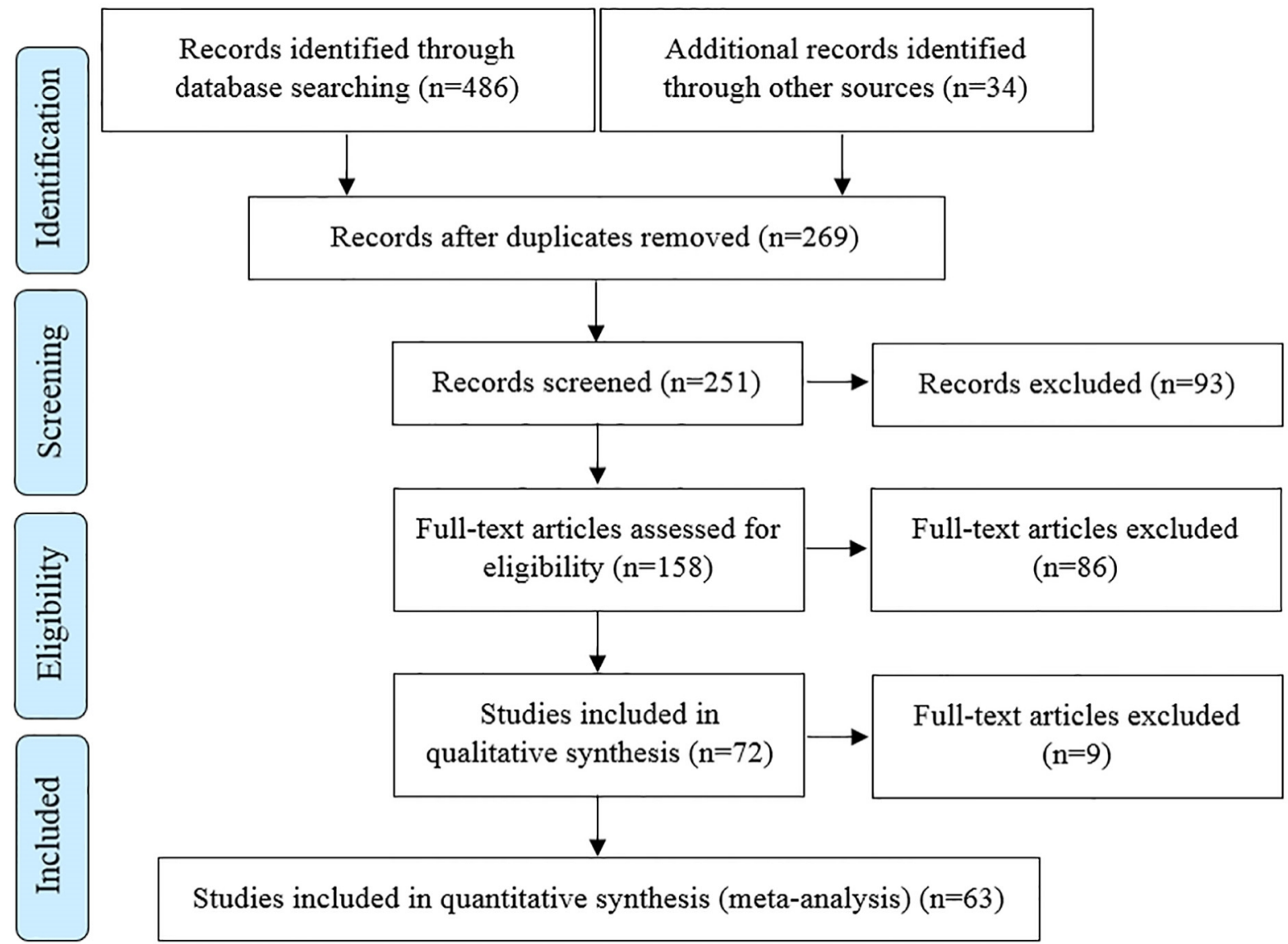

Figure 1. PRISMA flowchart of selecting the studies

\subsection{Characteristics of the included studies}

The number of participants in these studies was 36,833. Mirzaagha's study of 2,999 participants in Golestan province was the largest, and Najafi's study with 64 participants in Tehran province, was the smallest study. Studies were conducted between years 2003 and 2015. The participants' age in these studies varied between 5-57 years. Table (1) shows the characteristics of the included studies.

\subsection{Quality of studies}

After checking quality of included studies based on the STROBE checklist, 25 of them (39.6\%) were of highquality, 22 papers (34.9\%) were of average quality and 16 papers $(25.5 \%)$ were of low quality.

\subsection{Prevalence of celiac disease}

The overall prevalence of celiac disease in 63 studies that had used serological tests for the diagnosis, was observed as 3\% (95\% CI: $0.03-0.03$, I2: 90.9\%) (Figure 2). The number of participants in this study was 36,833. Besides, the overall prevalence of celiac disease in 41 studies that had used biopsy method for diagnosis, was observed as $2 \%$ (95\% CI: 0.01- 0.02, I2: 87.7\%) (Figure 3). The number of participants in this study was 24,538 . 
http://www.ephysician.ir

Table 1. Characteristics of studies included

\begin{tabular}{|c|c|c|c|c|c|c|}
\hline Athur & Year & City & Age & Sample size & Type of study & Quality of study \\
\hline Shahbazkhania & 2003 & Tehran & 35.5 & 2000 & Cross-sectional & Intermediate \\
\hline Shahbazkhani & 2004 & Tehran & 18.7 & 250 & Cross-sectional & Low \\
\hline Shahbazkhania & 2004 & Tehran & 31 & 100 & Cross-sectional & High \\
\hline Ale Yasin & 2004 & Tehran & 29.55 & 250 & Case-control & Intermediate \\
\hline Tirgar-Fakheri & 2004 & Sari & 35.5 & 1438 & Cross-sectional & Intermediate \\
\hline Farahmand & 2004 & Tehran & 13.9 & 35 & Cross-sectional & Intermediate \\
\hline Nikpour & 2005 & Tehran & 39 & 400 & Cross-sectional & Intermediate \\
\hline Khoshnia & 2005 & Gonbad-Kavoos & 50 & 1209 & Cross-sectional & Intermediate \\
\hline Sheikholeslami & 2005 & Ghazvin & 31.87 & 120 & Case-control & Intermediate \\
\hline Akbari & 2006 & Kerman-Sari & 33.7 & 2799 & Cross-sectional & Intermediate \\
\hline Joshaghani & 2006 & Golestan & 30 & 2547 & Cross-sectional & Intermediate \\
\hline Masoodi & 2007 & Bandar Abbas & 36.7 & 150 & Cross-sectional & High \\
\hline Nikpour & 2007 & Tehran & 40.3 & 126 & Prospective & Low \\
\hline Sharifi & 2008 & Tabriz & 25.35 & 250 & Case-control & Intermediate \\
\hline Saberi-Firouzi & 2008 & Shiraz & 45.3 & 1440 & Cross-sectional & Intermediate \\
\hline Hashemi & 2008 & Ahwaz & 16.8 & 104 & Cross-sectional & High \\
\hline Dehghani & 2008 & Shiraz & 9.8 & 72 & Cross-sectional & High \\
\hline Emami & 2008 & Tehran & 35.3 & 270 & Cross-sectional & Low \\
\hline khoshbaten & 2008 & Tabriz & 25.35 & 250 & Case-control & Intermediate \\
\hline Zamani & 2009 & Tehran & 36.7 & 288 & Cross-sectional & High \\
\hline Rostami-Nejad & 2009 & Tehran & 36 & 411 & Cross-sectional & High \\
\hline Ghahramani & 2009 & Arak & 40 & 810 & Case-control & Low \\
\hline khoshbaten & 2009 & Tabriz & 37 & 300 & Cross-sectional & Low \\
\hline Bahari & 2010 & Zahedan & 33.2 & 1600 & Cross-sectional & High \\
\hline Keshavarz & 2010 & Kermanshah & 31 & 170 & Cross-sectional & Intermediate \\
\hline Ghergherehchi & 2010 & Tabriz & 9.05 & 135 & Cross-sectional & Low \\
\hline Mirzaagha & 2010 & Tehran & 36.5 & 2999 & Cross-sectional & High \\
\hline Sima & 2010 & Tehran & 33.7 & 112 & Cross-sectional & Low \\
\hline Shahbazkhani & 2010 & Tehran & 39.79 & 100 & Cross-sectional & Low \\
\hline Farahmand & 2011 & Tehran & 7.18 & 301 & Cross-sectional & High \\
\hline Rahimi & 2011 & Tehran & 40.56 & 316 & Cross-sectional & High \\
\hline Norouzinia & 2011 & Tehran & 26 & 796 & Cross-sectional & Intermediate \\
\hline Rostami- Nejad & 2011 & Tehran & 36.1 & 407 & Cross-sectional & Low \\
\hline Bashiri & 2011 & Kermanshah & 18 & 241 & Cross-sectional & High \\
\hline Inaloo & 2011 & Shiraz & 10.6 & 1600 & Case-control & Intermediate \\
\hline Akhondi-Meybodi & 2011 & Yazd & 29.85 & 125 & Cross-sectional & Low \\
\hline Farahmand & 2012 & Tehran & 12.8 & 634 & Cross-sectional & High \\
\hline Bakhshipour & 2012 & Zahedan & 37.4 & 364 & Cross-sectional & High \\
\hline Emami & 2012 & Isfahan & 34.3 & 324 & Case-control & Intermediate \\
\hline Mehrdad & 2012 & Rasht & 39.46 & 454 & Cross-sectional & Low \\
\hline Khoshbaten & 2012 & Tabriz & 37 & 200 & Cross-sectional & High \\
\hline VosoghiniaH & 2012 & Mashhad & 19.78 & 87 & Cross-sectional & Intermediate \\
\hline Bakhshipour & 2013 & Zahedan & 37.4 & 403 & Cross-sectional & High \\
\hline Amini-Ranjbar & 2013 & Kerman & 6 & 144 & Cross-sectional & High \\
\hline Dehghani & 2013 & Shiraz & 9.5 & 1500 & Cross-sectional & High \\
\hline Houshiyar & 2013 & Ardabil & 31.4 & 105 & Cross-sectional & Low \\
\hline Jafarihaydarlo & 2013 & Ilam & 29.02 & 1000 & Cross-sectional & Low \\
\hline Hayatbakhsh & 2013 & kerman & 43 & 2259 & Cross-sectional & Intermediate \\
\hline Shaykhesmaili & 2013 & Sanandaj & 35.45 & 180 & Case-control & Low \\
\hline Ghergherehchil & 2013 & Tabriz & 12 & 200 & Cross-sectional & Intermediate \\
\hline Mahmoodi & 2014 & Ilam & 29.02 & 1000 & Cross-sectional & High \\
\hline Shayesteh & 2014 & Ahvaz & 31.8 & 465 & Cross-sectional & High \\
\hline Najafi & 2014 & Tehran & 8.39 & 64 & Cross-sectional & High \\
\hline Zahmatkeshan & 2014 & Shiraz & 5.73 & 82 & Case-control & Intermediate \\
\hline Honar & 2014 & Shiraz & 12.7 & 215 & Case-control & Low \\
\hline Yazdanbod & 2014 & Ardabil & 28.45 & 181 & Cross-sectional & Intermediate \\
\hline Honar & 2015 & Shiraz & 10.38 & 83 & Prospective & High \\
\hline Fallahi & 2015 & Tehran & 12 & 96 & Cross-sectional & Low \\
\hline Ahmadi & 2015 & kerman & 34.57 & 143 & Cross-sectional & High \\
\hline Dehghani & 2015 & Shiraz & 57.68 & 101 & Cross-sectional & Intermediate \\
\hline Shahramian & 2015 & Zahedan & 43.09 & 1002 & Case-control & High \\
\hline Jandaghi & 2015 & Tehran & 35.03 & 406 & Case-control & High \\
\hline Shahramian & 2015 & Zabol-Zahedan & 28.81 & 620 & Case-control & High \\
\hline
\end{tabular}




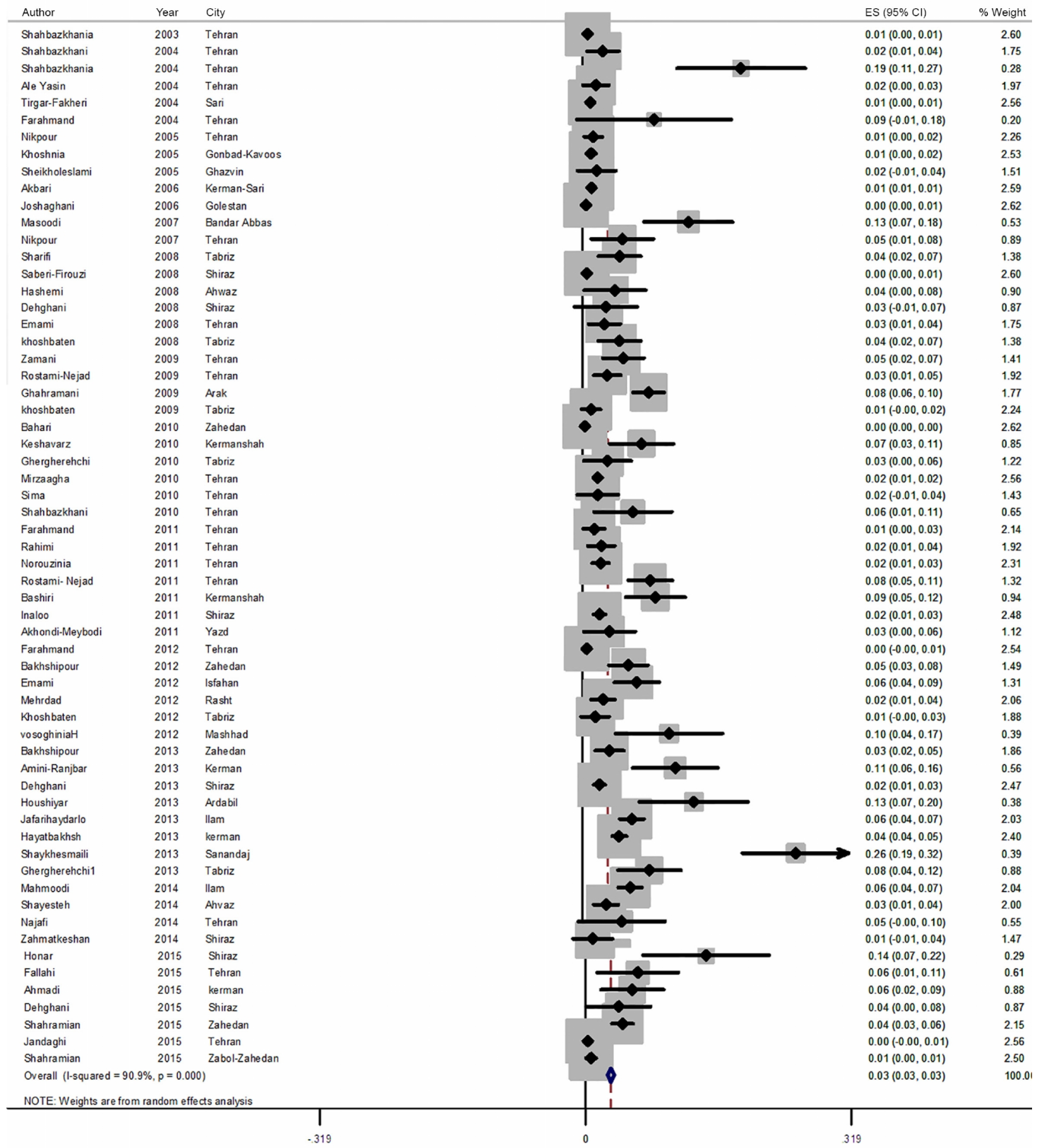

Figure 2. Forest plot of prevalence of celiac disease used serological tests

\subsection{Results of subgroup analysis}

The pooled prevalence was stratified according to age, sample size, the quality of studies, year of publication, and geographic area of studies in Table (2).

\subsection{Ages categories and prevalence of celiac disease}

The prevalence of celiac disease in studies that had used serological tests for the diagnosis was observed as 3\% (95\% CI: $0.03-0.06$ ) for the age group of less than ten years, 5\% (95\% CI: $0.03-0.06)$ for the age group 10 to 20 years, $3 \%$ (95\% CI: $0.02-0.04)$ for the age group of $20-30$ years, $3 \%(95 \% \mathrm{CI}$ : $0.02-0.04)$ for the age group $30-40$ 
years, $2 \%$ (95\% CI: $0.03-0.04)$ for the age group 40-50 years and 4\% (95\% CI: $0.00-0.04)$ for the age group 50 to 60 years. The prevalence of celiac disease in studies that had used duodenal biopsy for diagnosis was $2 \%$ (95\% CI: 0.00 -0.04) for the age group less than 10 years, 3\% (95\% CI: $0.01-0.04)$ for the age group $10-20$ years, $1 \%$ (95\% CI: 0.01-0.02) for the age group 20-30 years, $2 \%(95 \% \mathrm{CI}: 0.02-0.03)$ for the age group $30-40$ years, $0 \%$ ( $95 \% \mathrm{CI}$ : 0.01-0.03) for the age group 40-50 years, and 1\% (95\% CI: -0.01-0.03) for the age group 50-60 years.

\subsection{Sample size and prevalence of celiac disease}

The prevalence of celiac disease in studies that had used serological tests for the diagnosis was 4\% (95\% CI: 0.03 0.05 ) for studies with the sample size less than 800 participants, 3\% (95\% CI: $0.02-0.04)$ for studies with 800 to 1,600 participants, $2 \%$ (95\% CI: -0.01-0.06) for studies with 1,600 and 2,400 participants, and 1\% (95\% CI: $0.00-$ 0.02) for studies with more than 2,400 participants. Prevalence of celiac disease in studies that had used the duodenal biopsy for diagnosis was 3\% (95\% CI: 0.03-0.04) in sample sizes less than 800 participants, $0 \%$ (95\% CI: 0.00-0.01) for studies with 800-1,600 participants, $1 \%(95 \% \mathrm{CI}$ : $-0.00-0.01)$ for studies with 1,600-2,400 participants and $1 \%$ (95\% CI: 0.01-0.02) for studies with more than 2,400 participants.

\subsection{Quality of the studies included and prevalence of celiac disease}

The prevalence of celiac disease was observed for high-quality studies that had used serological tests for diagnosis as 3\% (95\% CI: 0.02-0.04), for studies of medium quality, 5\% (95\% CI: $0.04-0.07)$ and for low quality studies, $2 \%$ (95\% CI: 0.01-0.02). Prevalence of celiac disease in high-quality studies that had used the duodenal biopsy for diagnosis was 3\% (95\% CI: 0.02-0.03), for studies of medium quality, $1 \%$ (95\% CI: $0.01-0.01)$ and for poor quality studies, 4\% (95\% CI: 0.02-0.06).

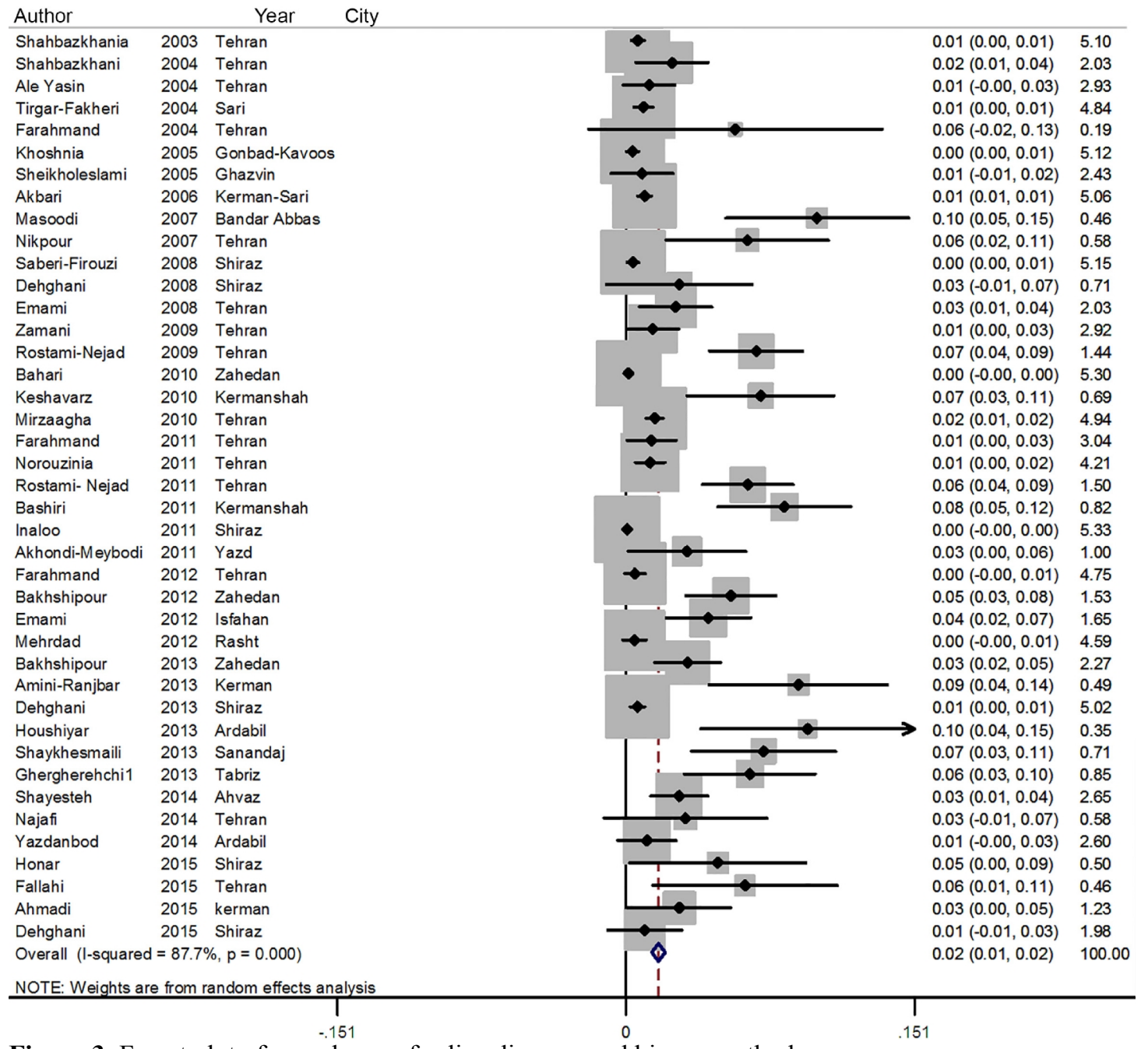

Figure 3. Forest plot of prevalence of celiac disease used biopsy method 


\subsection{Publication of year studies included and prevalence of celiac disease}

The prevalence of celiac disease in studies that had used serological tests for diagnosis and published in the years 2003-2007 was observed as $1 \%$ (95\% CI: $0.01-0.02)$ in the years $2007-2011,3 \%$ (95\% CI: $0.02-0.04)$ for the years 2011-2015 and 4\% (95\% CI: 0.03-0.05) in the years 2011-2015. The prevalence of celiac disease in studies that had used the duodenal biopsy for diagnosis and published was $1 \%(95 \% \mathrm{CI}: 0.01-0.01)$ in $2003-2007,2 \%(95 \% \mathrm{CI}$ : 0.01-0.02) for the years 2007 to 2011, and 3\% (95\% CI: 0.02-0.04) for the years 2011-2015.

Table 2. Results of subgroup analysis

\begin{tabular}{|c|c|c|c|c|c|c|c|c|c|}
\hline \multirow{2}{*}{\multicolumn{2}{|c|}{ Variables }} & \multicolumn{4}{|c|}{ Serological tests } & \multicolumn{4}{|l|}{ Marsh } \\
\hline & & Prevalence & $95 \% \mathrm{CI}$ & p-value & $\mathrm{I} 2(\%)$ & Prevalence & $95 \% \mathrm{CI}$ & p-value & I2 (\%) \\
\hline \multirow[t]{6}{*}{ Age (year) } & $<10$ & $3 \%$ & $1 \%-4 \%$ & 0.000 & 60.5 & $2 \%$ & $0 \%-4 \%$ & 0.012 & 74.4 \\
\hline & $10-20$ & $5 \%$ & $3 \%-6 \%$ & 0.000 & 86.4 & $3 \%$ & $1 \%-4 \%$ & 0.000 & 87.2 \\
\hline & $20-30$ & $3 \%$ & $2 \%-4 \%$ & 0.000 & 93.0 & $1 \%$ & $1 \%-2 \%$ & 0.000 & 0.0 \\
\hline & $30-40$ & $3 \%$ & $3 \% 4 \%$ & 0.000 & 91.7 & $2 \%$ & $2 \%-3 \%$ & 0.000 & 90.3 \\
\hline & $40-50$ & $2 \%$ & $1 \%-4 \%$ & 0.003 & 95.8 & $0 \%$ & $0 \%-1 \%$ & 0.003 & 0.0 \\
\hline & $50-60$ & $4 \%$ & $0 \%-4 \%$ & 0.041 & - & $1 \%$ & $-1 \%-3 \%$ & 0.315 & - \\
\hline \multirow[t]{4}{*}{ Sample size } & $<800$ & $4 \%$ & $3 \%-5 \%$ & 0.000 & 85.7 & $3 \%$ & $3 \%-4 \%$ & 0.000 & 82.0 \\
\hline & $800-1600$ & $3 \%$ & $2 \%-4 \%$ & 0.000 & 96.0 & $0 \%$ & $0 \%-1 \%$ & 0.002 & 73.3 \\
\hline & $1600-2400$ & $2 \%$ & $-1 \%-6 \%$ & 0.191 & 98.5 & $1 \%$ & $0 \%-1 \%$ & 0.001 & - \\
\hline & $>2400$ & $1 \%$ & $0 \%-2 \%$ & 0.008 & 93.0 & $1 \%$ & $1 \%-2 \%$ & 0.000 & 71.0 \\
\hline \multirow[t]{3}{*}{ Quality of the studies } & High & $3 \%$ & $2 \%-4 \%$ & 0.000 & 91.3 & $3 \%$ & $2 \%-3 \%$ & 0.000 & 90.0 \\
\hline & intermediate & $5 \%$ & $4 \%-7 \%$ & 0.000 & 88.1 & $1 \%$ & $1 \%-1 \%$ & 0.000 & 85.8 \\
\hline & Low & $2 \%$ & $1 \%-2 \%$ & 0.000 & 88.1 & $4 \%$ & $2 \%-6 \%$ & 0.000 & 83.5 \\
\hline \multirow[t]{3}{*}{ Year of publication } & $2003-2007$ & $1 \%$ & $1 \%-2 \%$ & 0.000 & 81.8 & $1 \%$ & $1 \%-1 \%$ & 0.000 & 73.9 \\
\hline & $2007-2011$ & $3 \%$ & $2 \%-4 \%$ & 0.000 & 90.0 & $2 \%$ & 1\%-2\% & 0.000 & 91.5 \\
\hline & 2011-2015 & $4 \%$ & $3 \%-5 \%$ & 0.000 & 81.8 & $3 \%$ & $2 \%-4 \%$ & 0.000 & 73.9 \\
\hline \multirow[t]{5}{*}{ Regional background } & Central & $3 \%$ & $2 \%-4 \%$ & 0.000 & 88.3 & $2 \%$ & $2 \%-3 \%$ & 0.000 & 81.8 \\
\hline & North & $1 \%$ & $0 \%-1 \%$ & 0.001 & 76.1 & $1 \%$ & $0 \%-1 \%$ & 0.004 & 46.0 \\
\hline & South & $2 \%$ & $1 \%-3 \%$ & 0.000 & 84.3 & $1 \%$ & $0 \%-1 \%$ & 0.003 & 83.8 \\
\hline & West & $5 \%$ & $4 \%-7 \%$ & 0.000 & 89.9 & $5 \%$ & $3 \%-8 \%$ & 0.000 & 85.0 \\
\hline & East & $4 \%$ & $2 \%-5 \%$ & 0.000 & 94.9 & $2 \%$ & $1 \%-3 \%$ & 0.000 & 91.0 \\
\hline
\end{tabular}

\subsection{Geographical background and prevalence of celiac disease}

The prevalence of celiac disease was 3\% (95\% CI: $0.02-0.04)$ in studies that had used serological tests for the diagnosis and were carried out in central Iran, $1 \%$ (95\% CI: $0.00-0.01)$ for studies conducted in northern Iran, $2 \%$ (95\% CI: 0.01-0.03) for studies conducted in the south. 5\% (95\% CI: $0.0-0.07)$ for studies conducted in West region of Iran and 4\% (95\% CI: 0.02-0.05) for studies conducted in eastern regions. The prevalence of celiac disease was $2 \%$ (95\% CI: 0.02-0.03) in studies that had used the duodenal biopsy for diagnosis, $1 \%$ (95\% CI: $0.00-0.01)$ for studies conducted in central Iran, $1 \%$ (95\% CI: 0.00-0.01) for studies carried out in northern Iran, $1 \%$ (95\% CI:0.000.01 ) for studies conducted in the south, $5 \%$ (95\% CI: $0.03-0.08)$ for studies conducted in West region and $2 \%(95 \%$ CI: 0.01-0.03) for studies performed in the eastern regions.

\subsection{Publication bias}

The results of the assessment of publication bias were observed in the studies that had used serological tests for the diagnosis, and were observed for the tests Begg $=0.000$, Egger $=0.000$, and for studies that had used duodenal biopsy for the diagnosis, Begg $=0.001$, Egger $=0.000$. The results suggest that publication bias has occurred.

\subsection{Sensitivity analysis}

To ensure strong results, we excluded Mirzaagha's study and conducted sensitivity analysis. For studies that had used serological tests, the prevalence remained unchanged and only CI 95\%, 3\% (95\% CI: 0.03-0.04) changed. For studies that had used the duodenal biopsy, no change was created in prevalence. Hence exclusion of this study did not have much effect on the results.

\subsection{Results of meta-regression}

Meta-regression results are shown in Table (3). Meta-regression for studies that had used serological tests showed that the prevalence of celiac disease increases based on the publishing year of studies, decreases based on 
participants' age, and increases based on a sample size of studies. But none are statistically significant. Metaregression for studies that had used the duodenal biopsy, reduced based on the participants, age, and none were significant, but significantly increased based on sample size.

Table 3. Results meta-regression analysis

\begin{tabular}{|c|c|c|c|c|c|c|c|c|c|c|c|c|}
\hline \multirow[t]{3}{*}{ Items } & \multicolumn{6}{|c|}{ Serological tests } & \multicolumn{6}{|l|}{ Marsh } \\
\hline & \multirow[t]{2}{*}{ Coefficient } & \multirow[t]{2}{*}{$\mathrm{SE}$} & \multirow[t]{2}{*}{$\mathrm{T}$} & \multirow[t]{2}{*}{$\mathrm{p}$} & \multicolumn{2}{|c|}{$95 \% \mathrm{CI}$} & \multirow[t]{2}{*}{ Coefficient } & \multirow[t]{2}{*}{ SE } & \multirow[t]{2}{*}{$\mathrm{T}$} & \multirow[t]{2}{*}{$\mathrm{p}$} & \multicolumn{2}{|c|}{$95 \% \mathrm{CI}$} \\
\hline & & & & & Lower & Upper & & & & & Lower & Upper \\
\hline Year & -0.00 & -0.11 & 0.34 & 0.95 & 0.00 & 0.00 & 0.00 & 0.00 & 0.60 & 0.55 & -0.00 & 0.00 \\
\hline Age & -0.00 & -0.00 & 0.86 & 0.17 & 0.00 & 0.00 & -0.00 & 0.00 & -0.20 & 0.83 & -.000 & 0.00 \\
\hline Samp & -2.28 & -.000 & 0.02 & -2.36 & -6.41 & 0.00 & -0.00 & 5.04 & -2.90 & 0.00 & -.000 & -4.38 \\
\hline Cons & 3.01 & -8.25 & 0.35 & -0.93 & 2.81 & -2.62 & -1.35 & 2.32 & -0.58 & -0.56 & -6.05 & 3.35 \\
\hline
\end{tabular}

\subsection{Results of cumulative meta-analysis}

For cumulative meta-analysis, studies and samples were ranked according to year of publication. Prevalence was declining for studies that used serological tests, when they were ranked according to year of publication and sample size. For studies that used duodenal biopsy, a decreasing prevalence was observed when studies were ranked according to year of publication and sample size.

\section{Discussion}

This study is the first systematic review and meta-analysis of celiac disease in Iran. The prevalence of celiac disease in different parts of Iran was studied. The results showed that the prevalence was 3\% (95\% CI: $0.03-0.03)$ for studies which used serological methods for diagnosis and 2\% (95\% CI: $0.01-0.02)$, for those used biopsy method for diagnosis. The prevalence of celiac disease was $0.71 \%$ in a study carried out in America (90) based on serological tests and 1.5\% in Finland on the basis of conducted serological tests (91). In another study in Saudi Arabia (92), the prevalence rate was $3 \%$ and $1 \%$ respectively on the basis of serological tests and biopsy method. The results show that the prevalence of celiac disease in Iran is more than in developed countries and is almost identical to the developing countries. Differences in the prevalence difference, between developed and developing countries, may be due to ideal health status, better servicing, and more advanced medical equipment in developed countries. The difference observed between the prevalence of serological tests and a biopsy method in the present study, is often due to lack of proper and accurate use of biopsy for the diagnosis of celiac disease in the developing countries (93). Unfortunately, in many cases, the diagnosis of celiac disease is solely based on serological tests. Factors such as intestinal parasitic and bacterial infections and malnutrition can cause changes in intestinal tissue similar to celiac disease characteristics. This could be the reason for the high prevalence of celiac disease in studies that have used serological tests. Our results showed that the lack of cohesion in the diagnostic criteria for celiac disease could be one reason for heterogeneity among studies based on p-value of Chi-square Test and I2. Additionally, high heterogeneity observed in this study may be due to the high number of studies and their sample size. Dietary habits can play an important role in the increased prevalence of celiac disease in respective countries. In the Iranian people's diet, grain and especially "Wheat", is widely consumed and this is an important factor for the increase in celiac disease. Celiac disease is rising not only in developed countries but in developing regions such as the Middle East, South Asia, North East, West Africa, and South America where taking a diet of grains, especially wheat, is common (94). Serologic tests are required in Iran for screening groups at risk to identify the disease. The prevalence of celiac disease is in all age groups up to 20 years. Given that traditional methods for breastfeeding and prolonged feeding with this practice and not cutting it at the right time is responsible for mild symptoms in these patients, these eating habits create a protecting effect for gluten intolerance in these individuals and a factor for more difficult reorganization of celiac disease (95). According to the study results, the prevalence of celiac disease is more common in the central and western regions of Iran. The high prevalence of celiac disease in these areas is because of the great city of Tehran. High population density, wrong eating habits, different ethnicities, population access to diagnostic centers of this disease can cause high prevalence in central Iran. Moreover, the prevalence of celiac disease is very high in Western Iran. Wheat consumption in these areas is very high. In the present study, some limitations were observed which can be referred as follows: 1) High heterogeneity was observed due to variety of diagnostic methods of patients in studies, this factor can influence the results, 2) The studies data were not possible for investigating the prevalence of celiac disease in terms of gender, 3) Only $36.9 \%$ of studies were of high-quality, which can be a cause for bias, 4) In some studies, only a diagnostic method had been used, 5) Carrying a large number of studies in Tehran also could be a factor affecting the bias, 6) The various diseases in people in some studies could also be another factor to influence the results. In conclusion, data from our meta-analysis confirmed 
higher serological tests for the diagnosis compared to biopsy method for diagnosis celiac disease. Further studies regarding the entire Iranian population and compared serological tests and biopsy method are needed to validate diagnosis celiac disease.

\section{Conclusions}

In conclusion, celiac disease in Iran has an estimated prevalence that was 3\% (95\% CI: 0.03-0.03) for studies which used serological methods for diagnosis and 2\% (95\% CI: $0.01-0.02)$ for those which used biopsy method for diagnosis. The prevalence of celiac disease in Iran was similar or even higher than that reported world-wide.

\section{Acknowledgments:}

The authors are grateful to the reviewers for their constructive comments, which improved the manuscript.

\section{Conflict of Interest:}

There is no conflict of interest to be declared.

\section{Authors' contributions:}

All authors contributed to this project and article equally. All authors read and approved the final manuscript.

\section{References:}

1) Husby S, Koletzko S, Korponay-Szabó IR, Mearin ML, Phillips A, Shamir R, et al. European Society for Pediatric Gastroenterology, Hepatology, and Nutrition guidelines for the diagnosis of coeliac disease. J Pediatr Gastroenterol Nutr. 2012; 54(1): 136-60. doi: 10.1097/MPG.0b013e31821a23d0. PMID: 22197856.

2) Tollefsen S, Arentz-Hansen H, Fleckenstein B, Molberg O, Ráki M, Kwok WW, et al. HLA-DQ2 and DQ8 signatures of gluten T cell epitopes in celiac disease. J Clin Invest. 2006; 116(8): 2226-36. doi: 10.1172/JCI27620. PMID: 16878175, PMCID: PMC1518792.

3) Schuppan D, Zimmer KP. The diagnosis and treatment of celiac disease. Dtsch Arztebl Int. 2013; 110(49): 835-46. PMID: 24355936, PMCID: PMC3884535.

4) Hu WT, Murray JA, Greenaway MC, Parisi JE, Josephs KA. Cognitive impairment and celiac disease. Arch Neurol. 2006; 63(10): 1440-6. doi: 10.1001/archneur.63.10.1440. PMID: 17030661.

5) West J, Logan RF, Hill PG, Lloyd A, Lewis S, Hubbard R, et al. Seroprevalence, correlates, and characteristics of undetected coeliac disease in England. Gut. 2003; 52(7): 960-5. doi: 10.1136/gut.52.7.960. PMID: 12801951, PMCID: PMC1773707.

6) Tatar G, Elsurer R, Simsek H, Balaban YH, Hascelik G, Ozcebe OI, et al. Screening of tissue transglutaminase antibody in healthy blood donors for celiac disease screening in the Turkish population. Dig Dis Sci. 2004; 49(9): 1479-84. doi: 10.1023/B:DDAS.0000042250.59327.91. PMID: 15481323.

7) Fasano A, Berti I, Gerarduzzi T, Not T, Colletti RB, Drago S, et al. Prevalence of celiac disease in at-risk and not-at-risk groups in the United States: a large multicenter study. Arch Intern Med. 2003; 163(3): 28692. doi: 10.1001/archinte.163.3.286. PMID: 12578508 .

8) Bingley PJ, Williams AJ, Norcross AJ, Unsworth DJ, Lock RJ, Ness AR, et al. Undiagnosed coeliac disease at age seven: population based prospective birth cohort study. BMJ. 2004; 328(7435): 322-3. doi: 10.1136/bmj.328.7435.322. PMID: 14764493, PMCID: PMC338097.

9) Katz KD, Rashtak S, Lahr BD, Melton LJ, Krause PK, Maggi K, et al. Screening for celiac disease in a North American population: sequential serology and gastrointestinal symptoms. Am J Gastroenterol. 2011; 106(7): 1333-9. doi: 10.1038/ajg.2011.21. PMID: 21364545, PMCID: PMC3130886.

10) Walker MM, Murray JA, Ronkainen J, Aro P, Storskrubb T, D'Amato M, et al. Detection of celiac disease and lymphocytic enteropathy by parallel serology and histopathology in a population-based study. Gastroenterology. 2010; 139(1): 112-9. doi: 10.1053/j.gastro.2010.04.007. PMID: 20398668, PMCID: PMC2902605.

11) Remes-Troche JM, Rios-Vaca A, Ramírez-Iglesias MT, Rubio-Tapia A, Andrade-Zarate V, RodríguezVallejo F, et al. High prevalence of celiac disease in Mexican Mestizo adults with type 1 diabetes mellitus. J Clin Gastroenterol. 2008; 42(5): 460-5. doi: 10.1097/MCG.0b013e318046ea86. PMID: 18344893.

12) Lohi S, Mustalahti K, Kaukinen K, Laurila K, Collin P, Rissanen H, et al. Increasing prevalence of coeliac disease over time. Aliment Pharmacol Ther. 2007; 26(9): 1217-25. doi: 10.1111/j.1365-2036.2007.03502.x. PMID: 17944736. 
13) Mustalahti K, Catassi C, Reunanen A, Fabiani E, Heier M, McMillan S, et al. The prevalence of celiac disease in Europe: results of a centralized, international mass screening project. Ann Med. 2010; 42(8): 587-95. doi: 10.3109/07853890.2010.505931. PMID: 21070098.

14) Shahbazkhani B, Malekzadeh R, Sotoudeh M, Moghadam KF, Farhadi M, Ansari R, et al. High prevalence of coeliac disease in apparently healthy Iranian blood donors. Eur J Gastroenterol Hepatol. 2003; 15(5): 475-8. doi: 10.1097/00042737-200305000-00003. PMID: 12702902.

15) Abu-Zekry M, Kryszak D, Diab M, Catassi C, Fasano A. Prevalence of celiac disease in Egyptian children disputes the east-west agriculture-dependent spread of the disease. J Pediatr Gastroenterol Nutr. 2008; 47(2): 136-40. doi: 10.1097/MPG.0b013e31815ce5d1. PMID: 18664863.

16) Catassi C, Rätsch IM, Gandolfi L, Pratesi R, Fabiani E, El Asmar R, et al. Why is coeliac disease endemic in the people of the Sahara? Lancet. 1999; 234(9179): 647-8. doi: 10.1016/S0140-6736(99)02609-4. PMID: 10466670.

17) Dinler G, Atalay E, Kalayci AG. Celiac disease in 87 children with typical and atypical symptoms in Black Sea region of Turkey. World J Pediatr. 2009; 5(4): 282-6. doi: 10.1007/s12519-009-0053-y. PMID: 19911143.

18) Barada K, Bitar A, Mokadem MA, Hashash JG, Green P. Celiac disease in Middle Eastern and North African countries: a new burden? World J Gastroenterol. 2010; 16(12): 1449-57. doi: 10.3748/wjg.v16.i12.1449. PMID: 20333784, PMCID: PMC2846249.

19) Bai D, Brar P, Holleran S, Ramakrishnan R, Green PH. Effect of gender on the manifestations of celiac disease: evidence for greater malabsorption in men. Scand J Gastroenterol. 2005; 40(2): 183-7. doi: 10.1080/00365520510011498. PMID: 15764149.

20) Fasano A, Catassi C. Current approaches to diagnosis and treatment of celiac disease: an evolving spectrum. Gastroenterology. 2001; 120(3): 636-51. doi: 10.1053/gast.2001.22123. PMID: 11179241.

21) Oberhuber G, Granditsch G, Vogelsang H. The histopathology of coeliac disease: time for a standardized report scheme for pathologists. Eur J Gastroenterol Hepatol. 1999; 11(10): 1185-94. doi: 10.1097/00042737-199910000-00019. PMID: 10524652.

22) Vandenbroucke JP, Von Elm E, Altman DG, Gøtzsche PC, Mulrow CD, Pocock SJ, et al. Strengthening the Reporting of Observational Studies in Epidemiology (STROBE): explanation and elaboration. PLoS Med. 2007; 4(10): e297.

23) DerSimonian R, Laird N. Meta-analysis in clinical trials. Control Clin Trials. 1986; 7(3): 177-88. doi: 10.1016/0197-2456(86)90046-2. PMID: 3802833.

24) Higgins JPT, Green S. Cochrane Handbook for Systematic Reviews of Interventions Version 5.1.0 London, UK: The Cochrane Collaboration; 2011.

25) Egger M, Davey Smith G, Schneider M, Minder C. Bias in meta-analysis detected by a simple, graphical test. BMJ. 1997; 315(7109): 629-34. doi: 10.1136/bmj.315.7109.629. PMID: 9310563, PMCID: PMC2127453.

26) Begg CB, Mazumdar M. Operating characteristics of a rank correlation test for publication bias. Biometrics. 1994; 50(4): 1088-101. doi: 10.2307/2533446. PMID: 7786990.

27) Ahmadi B, Zaherara M. Prevalence of Celiac Disease in Patients with Irritable Bowel Syndrome in Kerman, Iran. J Kerman Univ Med Sci. 2015; 20(3): 319-27.

28) Akbari MR, Mohammadkhani A, Fakheri H, Zahedi MJ, Bijan Shahbazkhani B, Nouraie M, et al. Screening of the adult population in Iran for coeliac disease: comparison of the tissue-transglutaminase antibody and anti-endomysial antibody tests. Eur J Gastroenterol Hepatol. 2006; 18(11): 1181-6. doi: 10.1097/01.meg.0000224477.51428.32. PMID: 17033439.

29) Akhondi-Meybodi M, Rabei A, Salehi S. Frequency of celiac disease in irritable bowel syndrome patients with predominant diarrhea referred to gastroenterology clinics in Yazd, Iran. J Shahid Sadoughi Univ Med Sci. 2011; 19(5): 637-43.

30) Al Yasin A, Forotan M, Forotan M, Akbari R, Agha Hosseini M, Sotoudeh M. Celiac disease in women with unexplained infertility in Shariati Hospital. Tehran Uni Med J. 2005; 62(5): 389-93.

31) Amini-Ranjbar S, Rezapour AH, Nakhaee N. Screening for Celiac Disease in Growth Retarded Children with or without Chronic Diarrhea: a Study on Children in Kerman/Iran. J Kerman Uni Med Sci. 2013; 20(2): 109-14.

32) Bahari A, Karimi M, Sanei-Moghaddam I, Firouzi F, Hashemi M. Prevalence of Celiac Disease among Blood Donors in Sistan and Balouchestan Province, Southeastern Iran. Arch Iran Med. 2010; 13(4): 301 10. doi: 010134/AIM.009. PMID: 20597563. 
33) Bakhshipour A, Kaykhaei MA, Moulaei N, Mashhadi MA. Prevalence of coeliac disease in patients with non-alcoholic fatty liver disease. Arab Journal of Gastroenterology. 2013; 14: 113-5. doi: 10.1016/j.ajg.2013.08.001. PMID: 24206739.

34) Bakhshipour A, Nezam SK, Zakeri Z, Gharibi R, Bahari Mahmoud A, Kaykhaeia A. Coeliac disease in irritable bowel syndrome (Rome III) in Southeast Iran. Arab Journal of Gastroenterology. 2012; 13: 24-7. doi: 10.1016/j.ajg.2012.03.003. PMID: 22560821.

35) Bashiri H, Keshavarz AA, Madani H, Hooshmandi AR, Bazargan-Hejazi SH, Ahmadi AR. Celiac disease in type-I diabetes mellitus: coexisting phenomenon. J Res Med Sci. 2011; 16 Suppl 1: S401-6. PMID: 22247725, PMCID: PMC3252773.

36) Dehghani SM, Asadi-Pooya AA. Celiac Disease in Children with Short Stature. Indian J Pediatr. 2008; 75 : 131-3. doi: 10.1007/s12098-008-0019-4. PMID: 18334792.

37) Dehghani SM, Ehsaei Z, Honar N, Javaherizadeh H. Frequency of Celiac Disease In Children With Chronic Functional Constipation in Shiraz-Iran. Middle East J Dig Dis. 2015; 7: 166-9. PMID: 26396719, PMCID: PMC4560631.

38) Dehghani SM, Haghighat M, Mobayen A, Rezaianzadeh A, Geramizadeh B. Prevalence of celiac disease in healthy Iranian school children. Ann Saudi Med. 2013; 33(2): 159-61. doi: 10.5144/0256-4947.2013.159. PMID: 23563005.

39) Emami MH, Kouhestani S, Gholamrezaei, Hashemi M, Mahzouni P, Raeisi M, et al. Prevalence of celiac disease in patients with irritable bowel syndrome. Govaresh. 2008;13:192-7

40) Emami MH, Kouhestani S, Karimi S, Baghaei A, Janghorbani M, Jamali N, et al. Frequency of Celiac Disease in Adult Patients with Typical or Atypical Malabsorption Symptoms in Isfahan, Iran. Gastroenterol Res Pract. 2012; 6: 134-42. doi: 10.1155/2012/106965. PMID: 22545042, PMCID: PMC3321539.

41) Fallahi Gh, Ahmadian JH, Rabani A, Yousefnejad D, Rezaie N. Screening for Celiac Disease in Diabetic Children from Iran. Indian Pediatr. 2010; 47(3): 268-70. PMID: 19430065.

42) Farahmand F, Mir-Nasseri MM, Shahraki T, Yourdkhani F, Ghotb S, Modaresi V, et al. Prevalence of Occult Celiac Disease in Healthy Iranian School Age Children. Arch Iran Med. 2012; 15(6): 342-5. doi: 012156/AIM.005, PMID: 22642242.

43) Farahmand F, Modaresi V, Najafi M, Khodadad A. Prevalence of Celiac Disease in Iranian Children with Recurrent Abdominal Pain Referred to a Pediatric Referral Center. Iran J Pediatr. 2011; 21(1): 33 -8. PMID: 23056761, PMCID: PMC3446100.

44) Farahmand F, Sotoudeh A. Celiac disease in children with insulin-dependent diabetes (type 1). Tehran Uni Med J. 2005; 65(11): 908-12.

45) Ghahramani R, Sadoogh Abbasian A, Shafaee S. Prevelence of Celiac Disease in Patients with Different Types of Dyspepsia. J Isfahan Med School. 2009; 27(93): 65-73.

46) Ghergherehchi R, Rafeey M, Hazhir N. Frequency of Celiac Disease in Short Stature Children in NorthWest of Iran. J Tabriz Uni Med Sci Health Serv. 2013; 13(5): 60-5.

47) Ghergherehchi R, Rafeey M, Majidi J, Majidi S. Prevalence of Celiac Disease in Type 1 Diabetic Children and adolescents in East Azarbaijan. J Babol Univ Med Sci. 2010; 11(6): 40-5.

48) Hashemi J, Hajiani E, Masjedizadeh R, Ghasemi N. Prevalence of celiac disease in Iranian children with idiopathic short stature. World J Gastroenterol. 2008; 14(48): 7376-80. doi: 10.3748/wjg.14.7376. PMID: 19109872, PMCID: PMC2778122.

49) Hayatbakhsh M, Zahedi MJ, Darvishmoghaddam S, Seyedmirzaie M, Najafipour M, Haghdoust AA, et al. The Prevalence of Irritable Bowel Syndrome, and its Clinical Symptoms and Related Factors among the Adult Population of Kerman, Iran. J Kerman Uni Med Sci. 2013; 20(4): 331-42

50) Honar N, Kamali S, Karimi M. Frequency of Celiac Disease in Children with Beta Thalassemia major. Iranian Journal of Pediatric Hematology Oncology. 2014; 4(2): 14-9.

51) Honar N, Karamizadeh Z, Saki F. Prevalence of celiac disease in patients with type 1 diabetes mellitus in the south of Iran. Turk J Gastroenterol. 2013; 14(4): 19-28. doi: 10.4318/tjg.2013.0541.

52) Houshiyar A, Fouladi N, Amani F, Alimohammadi Asl H, Ghorbani F. Prevalence of celiac disease in patients with irritable bowel syndrome in Ardabil-Iran (2009-10). J Gorgan Uni Med Sci. 2013; 14(4): 1259.

53) Inallo S, Dehghani SM, Farzadi F, Haghighat M, Imanieh MH. A comparative study of celiac disease in children with migraine headache and a normal control group. Turk J Gastroenterol. 2011; 22(1): 32-5. doi: 10.4318/tjg.2011.0153. PMID: 21480108. 
54) Jafarihaydarlo A, Mahmoodi AR, Yasemi M, Baziar A, Ehsanbakhsh S, Rashidbeygi M. Frequency of Celiac Disease in Patients with Diarrhea Predominant Irritable Bowel Syndrome Referred to Gastroenterology Clinics in Ilam During 2008 to 2012. J Ilam Uni Med Sci. 2013; 21: 191-8.

55) Jandaghi E, Hojatnia M, Vahedi H, Shahbaz-Khani B, Kolahdoozan SH, Ansari R. Is the Prevalence of Celiac Disease Higher than the General Population in Inflammatory Bowel Diseaese? Middle East J Dig Dis. 2015; 7(2): 82-7. PMID: 26106467, PMCID: PMC4430796.

56) Joshaghani HR, Semnani Sh, Mirrezaee A, Abdolahi N, Besharat S, Behnampour N, et al. Seroepidemiology of celiac disease among blood donor in Golestan province. J Gorgan Uni Med Sci. 2006; 8(3): 44-7.

57) Keshavarz AA, Bashiri H, Ahmadi AR, Bazargan-Hejazi SH. The Prevalence of Occult Celiac Disease among Patients with Functional Dyspepsia: A Study from the Western Region of Iran. Gastroenterol Res Pract. 2010; 4: 190-7. doi: 10.1155/2010/170702.

58) Khoshbaten M, Rostami Nejad M, Sharifi N, Fakhari A, Golamnejad M, Hashemi SH, et al. Celiac disease in patients with chronic psychiatric disorders. Gastroenterol Hepatol Bed Bench. 2012; 5(2): 90-3. PMID: 24834206, PMCID: PMC4017454.

59) Khoshbaten M, Sharifi N, Ali Askarzadeh A, Bahrami A. Celiac Disease in Type 1 Diabetic Patients Screened by Tissue Transglutaminase Antibodies in North-West of Iran. Med Sci J Islamic Azad Uni. 2008; 18(4): 239-44.

60) Khoshbaten M, Sharifi N, Gholamnejad M, Fakhari A. Seroprevalence of deliac disease among inpatients with chronic psychiatric disorders. Med Sci J Islamic Azad Uni. 2009; 19(9): 115-9.

61) Khoshnia M, Pourshams A, Mohammadkhani A, Tavangar SM, Shahbazkhani B, Malekzadeh R. Celiac Disease in Gonbad-Kavoos. Govaresh. 2005; 10(3): 131-4.

62) Mahmoodi A, Jafarihaydarlo A, Yasemi M, Hemati K, Peyman H. Celiac Disease Prevalence in thePatients with Irritable Bowel Syndrome in the Ilam Province; A Cross Sectional Study from Western Iran. J Clin Diagn Res. 2014; 8(12): GC01-3. doi: 10.7860/JCDR/2014/10175.5286. PMID: 25653962, PMCID: PMC4316268.

63) Masoodi M, Sadeghi S, Moosavi A. Celiac Disease in Patients with Irritable Bowel Syndrome. Govaresh. 2007; 12(3): 200-4.

64) Mehrdad M, Mansour-Ghanaei F, Mohammadi F, Joukar F, Dodangeh S, Mansour-Ghanaei R. Frequency of Celiac Disease in Patients with Hypothyroidism. J Thyroid Res. 2012; 6: 177-85. doi: $10.1155 / 2012 / 201538$.

65) Mirzaagha F, Hagh Azali S, Islami F, Zamani F, Khalilipour E, Khatibian M, et al. Coeliac disease in autoimmune liver disease: A cross-sectional study and a systematic review. Dig Liver Dis. 2014; 6(42): 620-3.

66) Najafi M, Sadjadei N, Eftekhari K, Motamed F, Fallahi GH, Farahmand F. Prevalence of Celiac Disease in Children with Autoimmune Hepatitis and vice versa. Iran J Pediat. 2014; 8(6): 723-8.

67) Nick Poor SH, Mohammad Hosseini A. Prevalence of Celiac Disease Endoscopic Index of non-ulcer dyspepsia in upper endoscopy patients in the hospital Loghman years 2003-2006. Pejouhandeh. 2007; 11(49): 21-4.

68) Nikpour Sh, Mohammad Hosseini E. Prevalence of Celiac Disease in Patients with Idiopathic Iron Deficiency of Referred to Gastroenterology Clinic. J Isfahan Med School. 2007; 25(4): 10-5.

69) Norouzinia M, Rostami K, Amini M, Lahmi F, Roshani M, Zojaji H, et al. Celiac disease; Prevalence and Outcome in Pregnancy. Health Med. 2011; 5(6): 23-34.

70) Rahimi A, Ebrahimi Daryani N, GHofrani H, Taher M, Pashaei MR, Abdolahzade S, et al. The prevalence of celiac disease among patients with non-alcoholic fatty liver disease in Iran. Turk J Gastroenterol. 2011; 22(3): 300-4. doi: 10.4318/tjg.2011.0216. PMID: 21805421.

71) Rostami Nejad M, Mahbobipour H, Fazeli Z, Mashayekhi R, Mirsattari D, Nazemalhosseini Mojarad E, et al. Celiac disease in dyspeptic patients. Koomesh. 2011; 12(2): 209-14.

72) Rostami Nejad M, Villanacci V, Mashayakhi R, Molaei M, Bassotti G, Zojaji H, et al. Celiac disease and HP infection association in Iran. Rev Esp Enferm Dig. 2009; 101(12): 850-4.

73) Saberi-Firouzi M, Omrani GR, Nejabat M, Mehrabani D, Khademolhosseini F. Prevalence of Celiac Disease in Shiraz, Southern Iran. Saudi J Gastroenterol. 2008; 14(3): 135-38. doi: 10.4103/13193767.41732. PMID: 19568522, PMCID: PMC2702920.

74) Shahbazkhani B, Faezi T, Akbari MR, Mohamadnejad M, Sotoudeh M, Raja A, et al. Coeliac disease in Iranian type I diabetic patients. Digestive and Liver Disease. 2004; 36: 191-4. doi: 10.1016/j.dld.2003.10.015. PMID: 15046188. 
75) Shahbazkhani B, Malekzadeh R, Sotoudeh M, Fayaz Moghadam K, Farhadi M, Ansari R, et al. High prevalence of coeliac disease in apparently healthy Iranian blood donors. Eur J Gastroenterol Hepatol. 2003; 15(5): 475-8. doi: 10.1097/01.meg.0000059118.41030.96. PMID: 12702902.

76) Shahbazkhani B, Mehrabi Gh, Nasiritosi M, Forotan H, Asefirad Sh. Celiac disease in cryptogenic hypertransaminasemia. Tehran Uni Med J. 2010; 68(7): 428-33.

77) Shahbazkhani B, Mohamadnejad M, Malekzadeh R, Akbaria MR, Moghari Esfahani M, NasseriMoghaddam S, et al. Coeliac disease is the most common cause of chronic diarrhoea in Iran. Eur J Gastroenterol Hepatol. 2004; 16(7): 665-8. doi: 10.1097/01.meg.0000108327.52416.c3. PMID: 15201579.

78) Shahramian I, Dehghani SM, Haghighat M, Noori NM, Teimouri AR, Sharafi E, et al. Serological Evaluation of Celiac Disease in Children with Congenital Heart Defect; A Case Control Study. Middle East J Dig Dis. 2015; 7(2): 98-103. PMID: 26106470, PMCID: PMC4430799.

79) Shahramian I, Dehghani SM, Haghighat M, Noori NM, Teimouri AR, Sharafi E, et al. Serologic evaluation of celiac disease in patients with beta thalassemia major and control. Gastroenterol Hepatol Bed Bench. 2015; 8(2): 153-9. PMID: 25926941, PMCID: PMC4403028.

80) Sharifi N, Khoshbaten M, Aliasgarzade A, Bahrami A. Celiac disease in patients with type-1 diabetes mellitus screened by tissue transglutaminase antibodies in northwest of Iran. Int J Diabetes Dev Ctries. 2008; 28(3): 95-9. doi: 10.4103/0973-3930.44081. PMID: 19902043, PMCID: PMC2772016.

81) Shayesteh AA, Hajiani E, Hashemi SJ, Masjedizadeh A, Latifi SM, Shayesteh M. Prevalence of celiac disease in Iranian patients with irritable bowel syndrome: A cross-sectional study. J Dig Dis. 2014; 15: 127. doi: 10.1111/1751-2980.12102. PMID: 24320042.

82) Shaykhesmaili F, Taheri A, Nikandish M, Gharibi F. Survey of Celiac Serology between Microscopic Colitis and Healthy People. Govaresh. 2013; 18: 95-9.

83) Sheikholeslami H, Boostani K, Hashemipoor S, Hadjmanoochehri F, Ziaii A. Compare frequency of celiac in patients with diabetic melitus type 1 and non-diabetic healthy persons. Iranian J Diabetes Metab Disord. 2005; 4(3): 49-55.

84) Sima HR, Hekmatdoost A, Ghaziani T, Alavian SM, Mashayekh A, Zali MR. The Prevalence of Celiac Autoantibodies in Hepatitis Patients. Iran J Allergy Asthma Immunol. 2010; 9(3): 157-62. PMID: 20952805.

85) Tirgar Fakheri H, Malekzadeh R, Akbari MR, Sotoudeh M. Prevalence of Celiac disease in north of Iran: Screening of an adult population in Sari. J Gorgan Uni Med Sci. 2004; 6(1): 94-100.

86) Vosughinia H, Nezam K, bayani M, Saadatnia H, Beygom Aboutorabi R, Bakhshipour A, et al. The Prevalence of Celiac Sprue in Adult Patients with Type I Diabetes. Med J Mashhad Uni Med Sci. 2012; 55(3): 178-82.

87) Yazdanbod A, Nemati R, Iranparvar Alamdari M, Azami A, Maleki N. Prevalence of Celiac Disease in Patients with Recurrent Aphthous Stomatitis. Govaresh. 2014; 18(4): 56-68.

88) Zahmatkeshan M, Fallahpoor M, Amoozgar H. Prevalence of Celiac Disease in Children with Idiopathic Dilated Cardiomyopathy. Iran J Pediat. 2014; 24(5): 587-92. PMID: 25793066 , PMCID: PMC4359412.

89) Zamani F, Shahram F, Shakeri R, Zayyeni H, Davatchi F, Amiri A, et al. Prevalence of Celiac Disease Among Patients with Behcet's Disease in Iran. Dig Dis Sci. 2009; 54: 1736-9. doi: 10.1007/s10620-0080548-8. PMID: 18989774.

90) Rubio-Tapia A, Ludvigsson JF, Brantner TL, Murray JA, Everhart JE. The prevalence of celiac disease in the United States. Am J Gastroenterol. 2012; 107(10): 1538-44. doi: 10.1038/ajg.2012.219. PMID: 22850429.

91) Mäki M, Mustalahti K, Kokkonen J, Kulmala P, Haapalahti M, Karttunen T, et al. Prevalence of Celiac disease among children in Finland. N Engl J Med. 2003; 348(25): 2517-24. doi: 10.1056/NEJMoa021687. PMID: 12815137.

92) Al Hatlani MM. Prevalence of celiac disease among symptom-free children from the Eastern Province of Saudi Arabia. Saudi J Gastroenterol. 2015; 21(6): 367-71. doi: 10.4103/1319-3767.170952. PMID: 26655131, PMCID: PMC4707804.

93) Lebenthal E, Branski D. Celiac disease: an emerging global problem. J Pediatr Gastroenterol Nutr. 2002; 35(4): 472-4. doi: 10.1097/00005176-200210000-00004. PMID: 12394370.

94) Cataldo F, Montalto G. Celiac disease in the developing countries: a new and challenging public health problem. World J Gastroenterol. 2007; 13(15): 2153-9. doi: 10.3748/wjg.v13.i15.2153. PMID: 17465493, PMCID: PMC4146836.

95) Ascher H. Paediatric aspects of coeliac disease: old challenges and new ones... Dig Liver Dis. 2002; 34(3): 216-24. doi: 10.1016/S1590-8658(02)80196-7. PMID: 11990395. 